DOI: $10.17516 / 1997-1370-0766$

УДК 304.2:001.4

\title{
The Nature of Communications in the Context of the Information Society Development: the Problems of Conceptual Apparatus Formation
}

\author{
Inna L. Skipor* \\ Kemerovo State University of Culture and Arts \\ Kemerovo, Russian Federation
}

Received 23.03.2021, received in revised form 13.04.2021, accepted 24.05.2021

\begin{abstract}
The research is aimed at identifying the characteristics of the conceptual apparatus of the subject area «information society», which is considered as the most important means of communication. The expansion of means of communication in the context of active introduction of information technologies into various fields of activity using both linguistic and non-linguistic signs is indicated. With the participation of representatives of various spheres of activity (IT-specialists, representatives of authorities and management, regulatory and supervisory and law enforcement agencies, information service providers and information technology users), who have different levels of vocabulary in the subject area «information society» in the communication process, information transfer is associated with its possible lack of understanding or complete misunderstanding by the communication participants. Despite the presence of publications devoted to the issues of standardization and the use of concepts characterizing various aspects of the information society formation and development in the modern documentary stream, there are no studies reflecting results of the system analysis of the term system of the subject area «information society». Based on the content analysis of the abstracts journal «Informatics», which reflects the global documentary flow (chronological coverage: 2000-2018) and Russian regulatory documents in the field of informatization of society, international and national (Russian) standards, the composition of the concepts used has been revealed. During the study of the composition and the content of the concepts definitions enshrined in regulatory and technical documents, such challenges of the conceptual apparatus formation as inconsistency of definitions used both in different industries and in different standards included in one complex or a system of standards; incorrect use of terms that have definitions enshrined in regulatory documents; parallel use of synonymous terms and concepts, including within the same field of activity, have been identified. It is proposed to consider increasing the efficiency of communications in the information society through solving a set of tasks: formation of a terminology system that meets the requirements of international and Russian regulatory documents, development of a classification of concepts that characterize the information society as a whole and its components; adaptation of the conceptual apparatus enshrined in normative
\end{abstract}

(C) Siberian Federal University. All rights reserved

* Corresponding author E-mail address: skiporil@mail.ru ORCID: 0000-0001-9608-7056 
legal and normative and technical documents; development of information retrieval thesauri, and complex reference editions.

Keywords: means of communication, communication channels, subject area «information society», informatization of society, conceptual apparatus, term system.

Research area: culturology.

Citation: Skipor, I.L. (2021). The nature of communications in the context of the information society development: the problems of conceptual apparatus formation. J. Sib. Fed. Univ. Humanit. Soc. Sci., 14(6), 862-872. DOI: 10.17516/1997-1370-0766.

\title{
Характер коммуникаций в условиях развития информационного общества: проблемы формирования понятийного аппарата
}

\author{
И.Л. Скипор \\ Кемеровский государственный институт культуры \\ Российская Федерачия, Кемерово
}

\begin{abstract}
Аннотация. Исследование направлено на выявление характеристик понятийного аппарата предметной области «информационное общество», который рассматривается как важнейшее средство коммуникации. Отмечается расширение средств коммуникации в условиях активного внедрения информационных технологий в различные сферы деятельности за счет использования как языковых, так и неязыковых знаков. При участии в коммуникационном процессе представителей различных сфер деятельности (IT-специалистов, представителей органов власти и управления, контрольно-надзорных, правоохранительных органов, провайдеров информационных услуг, пользователей информационных технологий), обладающих разным уровнем владения лексикой в предметной области «информационное общество», передача информации сопряжена с возможным ее недопониманием или полным непониманием участниками коммуникации. Несмотря на наличие в современном документальном потоке публикаций по проблемам нормирования и использования понятий, характеризующих различные аспекты формирования и развития информационного общества, отсутствуют работы, отражающие результаты системного анализа терминосистемы предметной области «информационное общество». На основе контент-анализа реферативного журнала «Информатика», отражающего мировой документальный поток (хронологический охват: 2000-2018 гг.), российских нормативноправовых документов в сфере информатизации общества, международных и национальных (российских) стандартов определен состав используемых понятий. В ходе исследования состава и содержания дефиниций понятий, закрепленных нормативно-правовыми и нормативно-техническими документами, выявлены проблемы формирования понятийного аппарата: несогласованность определений, используемых как в разных отраслях деятельности, так и в разных стандартах, входящих в один комплекс или систему стандартов; некорректное
\end{abstract}


обращение с терминами, имеющими дефиниции, закрепленные в нормативных документах; параллельное использование синонимичных терминов и понятий, в том числе в пределах одной сферы деятельности. Повышение эффективности коммуникаций в информационном обществе предлагается рассматривать через решение комплекса задач: формирование терминосистемы, соответствующей требованиям международных и российских нормативных документов, разработка классификации понятий, характеризующих информационное общество в целом и его компоненты; сопряжение понятийного аппарата, закрепляемого нормативноправовыми и нормативно-техническими документами; разработка информационнопоисковых тезаурусов, комплексных справочных изданий.

Ключевые слова: средства коммуникации, каналы коммуникации, предметная область «информационное общество», информатизация общества, понятийный аппарат, терминосистема.

Научная специальность: 24.00.00 - культурология.

Высокие темпы развития информационных технологий и их повсеместное внедрение практически во все сферы жизни и деятельности современного человека стимулировали и изменение коммуникативной среды. Вовлеченность в различные производственные, общественные и иные процессы, реализуемые с использованием информационных (в том числе информационно-коммуникационных) технологий, определили необходимость диверсификации средств коммуникации, расширение состава применяемых знаковых систем, каналов коммуникации.

Переход от аналоговой к цифровой информационной среде обусловил необходимость использования различных знаковых систем, поскольку они, с одной стороны, служат для организации этой среды, a с другой - предназначены для передачи информации, обеспечения общения среди пользователей. В первом случае речь идет об использовании преимущественно неязыковых знаков, которые применяются в структуре интерфейсов информационных систем, баз данных, браузеров и т. п. (например, пиктограммы), для представления специфической информации - отражения форматов представления данных, сведений о владельцах ресурсов и т. п. (специальные знаки, знак копирайта), обозначения системы навигации (гиперссылки) и др. Организация данных в цифровой информационной среде, обеспечение поиска информации, взаимодействия пользователя с информационной системой требуют применения знаков кодовых систем (языков программирования, информационно-поисковых языков и т. п.).

Для решения задач передачи информации от отправителя к получателю, реализации диалога между пользователями системой или сетью важнейшими остаются вербальные средства коммуникации. Речь идет, главным образом, о естественном языке. Следует заметить, что в качестве средств сетевого общения часто используют и неязыковые знаки (смайлы), однако их применение носит в большей степени вспомогательный характер.

Глобальный масштаб внедрения информационных технологий, создание информационной инфраструктуры обусловили широкое распространение лексики, характеризующей различные аспекты формирования и развития информационного общества. Понятия данной предметной области используют специалисты разных сфер деятельности, в том числе:

- представители органов власти и управления, формирующие политику в сфере информатизации общества;

- специалисты, профессионально занимающиеся вопросами разработки, внедрения, сопровождения и модернизации информационных технологий; 
- провайдеры информационных услуг;

- пользователи информационных технологий, круг которых достаточно широк (практически он охватывает все слои населения), поскольку применение ими информационных технологий обусловлено различными задачами, в том числе задачами профессиональной деятельности, образования, организации досуга, решения социальных вопросов и др.;

- представители контрольнонадзорных, правоохранительных органов, регулирующие правовые аспекты информатизации общества.

В условиях, когда участниками коммуникационного процесса являются представители различных сфер деятельности, обладающие разным уровнем владения лексикой в предметной области «информационное общество», при передаче информации возможно недопонимание или полное непонимание участниками коммуникации. Это происходит в результате непреднамеренного искажения информации. Причинами коммуникативных неудач могут быть логические, стилистические и семантические (смысловые) барьеры. Устранение данных барьеров в условиях развития информационного общества может осуществляться, прежде всего, за счет разработки основанного на принципах системности и целостности понятийного аппарата и закрепления его в нормативных документах международного и национального уровней, формирования информационной культуры личности. В рамках настоящей статьи рассмотрены проблемы формирования понятийного аппарата, поскольку именно он является важнейшим средством взаимопонимания различных субъектов информационного общества.

\section{Отражение проблем формирования понятийного аппарата предметной области «информатизация общества» в современном документальном потоке}

Анализ современного документального потока свидетельствует об интересе уче- ных из различных предметных областей к проблеме нормирования и использования понятий, характеризующих различные аспекты формирования и развития информационного общества. Так, специалисты библиотечно-информационной сферы подчеркивают важность унификации лексики. Прежде всего, речь идет о правомерности использования отдельных терминов и понятий, характеризующих информационные ресурсы, а также об их дефинициях. Так, на страницах научного журнала «Научные и технические библиотеки» опубликованы дискуссионные статьи Ю.Н. Столярова (Stolyarov, 2016) и Т.Ф. Берестовой (Berestova, 2017) в отношении целесообразности использования понятия «информационные ресурсы». В разделе данного журнала «Дискуссионный клуб «Термин»» также обсуждалась терминология «открытого доступа» (Zemskov, 2016; Stolyarov, 2016; Shrayberg, 2016). Попытка выявить основные подходы к определению понятия «электронный документ» и проблемы, связанные с выработкой единого определения понятия, представлены А. Ю. Камаловым (Kamalov, 2015). Автором рассмотрен генезис понятия «электронный документ», исследованы актуальные вопросы правового обеспечения электронных документов, прежде всего использование электронной подписи как средства придания электронным документам юридической силы. Анализу базовых понятий, характеризующих электронные документы, посвящена статья Е.В. Динер (Diner, 2016). Результаты анализа терминосистемы предметной области «электронные информационные ресурсы» отражены в работе Н.И. Колковой и И. Л. Скипор (Kolkova, Skipor, 2016). Исследователями предпринята попытка сравнить отраженные в межгосударственных и национальных стандартах Российской Федерации понятия, характеризующие электронные информационные ресурсы, с лексикой, используемой при отражении электронных информационных ресурсов в составе контента сайтов центральных библиотек субъектов Российской Федерации. 
В особой мере наличие единого понятийного аппарата актуально для правовой сферы, поскольку разное понимание одних и тех же понятий ведет к серьезным проблемам в сфере правового регулирования. Так, статья И.Д. Кузьминой и И.С. Богданова посвящена исследованию проблем, возникающих в результате воздействия современной цифровой среды на такие традиционные категории гражданского права, как объект и субъект правоотношений (Kuzmina, Bogdanova, 2019). Исследованию закономерностей развития понятийного аппарата в сфере Интернета, информационных технологий и правовой идентификации в информационном пространстве посвящена статья В.Б. Наумова (Naumov, 2018). В работе приводятся результаты комплексного анализа и примеры, характеризующие постепенное разрушение единой непротиворечивой терминологической системы информационного законодательства. Автором отмечается особая значимость классификации и описания закономерностей формирования понятийного аппарата при развитии нормотворчества, включая сферу цифровой экономики. Роль терминов в упорядочении источников права с учетом значимости проблем информационной безопасности рассмотрена в работе И. Л. Бачило (Bachilo, 2016).

Несмотря на наличие достаточно большого количества публикаций проблемного и дискуссионного характера по вопросам формирования понятийного аппарата, характеризующего различные компоненты информационного общества, отсутствуют работы, отражающие результаты системного анализа терминосистемы данной предметной области.

\section{Содержание}

\section{и результаты исследования}

Цель исследования: получение данных, характеризующих состояние понятийного аппарата предметной области «информационное общество» как важнейшего средства коммуникации.

Следует заметить, что исследование является лишь попыткой обозначить про- блему отсутствия целостной непротиворечивой терминосистемы такой масштабной, многокомпонентной и сложной предметной области, как предметная область «информационное общество». Поэтому в отношении данной предметной области весьма затруднительно четкое определение ее семантических и формальных границ. В данном контексте на формирование понятийного аппарата предметной области «информационное общество», безусловно, оказывают существенное влияние присущие ей специфические особенности, к числу которых можно отнести:

- глобальный характер процессов построения и развития информационного общества и, как следствие, распространение характеризующих их терминов и понятий на разные сферы деятельности как на национальном, так и транснациональном уровне;

- высокие темпы обновления знаний, интенсивное развитие информационных технологий, их обновление и, соответственно, сопровождающее этот процесс появление новых понятий;

- широкий круг субъектов, которые вводят новые понятия и используют их для решения разноплановых задач;

- активное заимствование терминов и понятий из других языков, прежде всего англоязычных терминов и понятий;

- необходимость правового регулирования деятельности в сфере создания, распространения, использования информационных ресурсов и технологий.

В качестве базы исследования выступили: реферативный журнал (РЖ) «Информатика», отражающий мировой документальный поток в данной сфере (хронологический охват: 2000-2018 гг.); российские нормативно-правовые документы в сфере информатизации общества, отраженные в справочно-правовой системе «Консультант»; каталог международных и национальных (российских) стандартов, формируемый Федеральным агентством по техническому регулированию и метрологии (Росстандарт, www.gost.ru); справочные издания по информатике. 
В реферативном журнале «Информатика» анализу подлежали предметные рубрики, представленные в предметном указателе и обеспечивающие поиск отраженных в РЖ отечественных и зарубежных публикаций по заданному предмету. Проведенный анализ реферативного журнала позволил выявить перечень понятий, используемых различными авторами при рассмотрении вопросов развития информационного общества.

Поскольку важнейшим средством официального введения в общественный оборот и закрепления дефиниций понятий являются нормативные документы, особый интерес при проведении исследования вызывал анализ состава и содержания дефиниций понятий, отраженных в нормативноправовых и нормативно-технических документах. При этом анализировались понятия и их определения, представленные эксплицитно.

Основными методами исследования выступили контент-анализ и терминологический анализ. В качестве единиц анализа взяты как базовые понятия («информационное общество», «информатизация общества», «информационная инфраструктура»), так и понятия, характеризующие отдельные компоненты информационного общества («информационные технологии», «информационно-коммуникационные технологии», «цифровые технологии», «сайты», «электронная информация», «электронные ресурсы», «электронные документы», «электронные библиотеки», «виртуальные библиотеки», «цифровые библиотеки» и др.).

В ходе проведенного анализа было установлено, что значительное количество понятий, используемых в научных публикациях отечественных и зарубежных авторов по проблемам развития информационного общества, имеют закрепленные нормативными документами дефиниции. К их числу относятся такие понятия, как: «информационное общество», «информатизация», «информационная инфраструктура», «информационное пространство», «информационные технологии», «информационно-коммуникационные технологии», «автоматизированная система», «база данных», «Интернет», «сайт в сети Интернет», «электронная библиотека», «электронный документ», «электронный ресурс», «электронное издание» и др.

Так, в «Стратегии развития информационного общества в Российской Федерации на 2017-2030 годы» (утв. Указом Президента РФ от 09.05.2017 N203) (Strategiia ..., 2017) закреплено понятие «информационное общество», под которым понимается общество, в котором информация и уровень ее применения и доступности кардинальным образом влияют на экономические и социокультурные условия жизни граждан. Следует отметить, что в настоящее время достаточно широко используется понятие «цифровое общество»: в названиях конференций, докладов, при изложении текстов федеральных целевых программ, научных статей, в устной речи. При этом зачастую данное понятие используется как синонимичное понятию «информационное общество». Тем не менее на нормативном уровне данное понятие не нашло своего закрепления.

Аналогичная ситуация наблюдается и в отношении понятий «информационные технологии», которое отражено в Федеральном законе «Об информации, информационных технологиях и о защите информации» (от 27.07.2006 N149-Ф3) (Ob informatsii ..., 2006) и в национальных стандартах (GOST R52653-2006, 2007), (GOST R43.0.9-2017, 2017), и «цифровые технологии», не нашедшее отражения в нормативной базе.

В качестве еще одного примера следует привести параллельное использование понятий «виртуальная библиотека», «цифровая библиотека» и «электронная библиотека». В 2016 г. в России принят национальный стандарт - ГОСТ Р 7.0.96-2016 «СИБИД. Электронные библиотеки. Основные виды. Структура. Технология формирования» (GOST R7.0. 96-2016, 2016), закрепивший понятие «электронная библиотека», под которым понимается «информационная система, предназначенная для организации и хранения упорядоченного фонда электрон- 
ных объектов, и обеспечения доступа к ним с помощью единых средств навигации и поиска». Данное понятие также закреплено принятым годом ранее ГОСТ Р 7.0.94-2015 «СИБИД. Комплектование библиотеки документами. Термины и определения», в котором содержится несколько иная дефиниция: «Электронная библиотека (electronic library/ e-library/ digital library) - упорядоченное собрание разнородных электронных документов (в том числе книг), локализованных в информационной системе, снабженных едиными средствами навигации и поиска и доступных через информационнотелекоммуникационные сети» (GOST R7.0.94-2015, 2016). Данный стандарт допускает использовать в качестве синонимов англоязычные термины «electronic library», «e-library», «digital library».

Тем не менее анализ предметного указателя РЖ «Информатика» свидетельствует о стабильном параллельном использовании понятий «виртуальная библиотека», «цифровая библиотека» и «электронная библиотека», которые отражаются на уровне предметных рубрик предметного указателя. В то же время содержание приводимых в них подрубрик указывает на перекрестные отсылки от наполнения рубрики «цифровая библиотека» к рубрике «электронная библиотека» и наоборот. Не вносит ясности и обращение к «Русско-английскому словарю по библиотечной и информационной деятельности» (Sukiasyan, Zverevich, Bakhturina, 2013), в котором приводятся англоязычные эквиваленты для всех трех понятий, при этом для понятия «электронная библиотека» эквивалентами являются «electronic library» и «digital library».

Поскольку информационная сфера активно заимствует термины из других языков (главным образом, англоязычные термины), неизбежно возникает проблема их адекватного перевода и использования в русскоязычных текстах. Аналогичная проблема возникает и при переводе текстов с русского языка на английский или иной язык. Так, анализ результатов перевода названий статей по вопросам развития информационного общества, размещенных в на- учной электронной библиотеке eLIBRARY. $\mathrm{RU}$, показывает, что слово «электронный» при переводе на английский язык имеет разные англоязычные эквиваленты: «electronic» и «digital». Во многом в данной ситуации выбор определяется переводчиком. Подробнее проблема осознания переводчиком культурных различий носителей исходного и переводящего языков, понимание им всех параметров коммуникативной ситуации создания текстов и способности оценить степень релевантности информации в принятии переводческих решений рассмотрены О. В. Петровой (Petrova, 2018).

Приведенные выше примеры являются лишь отдельной иллюстрацией имеющейся в настоящее время проблемы формирования понятийного аппарата предметной области «информационное общество». Не менее серьезной проблемой является рассредоточение определений понятий рассматриваемой предметной области в различных нормативно-правовых и нормативно-технических документах и их несогласованность. Прежде всего, речь идет об отражении одного и того же понятия и закрепление за ним отличных друг от друга дефиниций в разных законодательных документах, а также стандартах, входящих в состав различных комплексов и систем стандартов. Яркий тому пример - понятие «электронный документ», которое отражено в Федеральных законах Российской Федерации «Об информации, информационных технологиях и о защите информации» (от 27.07.2006 N149-Ф3) и «Об электронной подписи» (от 06.04.2011 N63-Ф3), ГОСТ 7.83-2001 «СИБИД. Электронные издания. Основные виды и выходные сведения», ГОСТ Р 7.0.83-2013 «СИБИД. Электронные издания. Основные виды и выходные сведения», ГОСТ Р 7.0.82013 «СИБИД. Делопроизводство и архивное дело. Термины и определения», ГОСТ Р 7.0.95-2015 СИБИД. Электронные документы. Основные виды, выходные сведения, технологические характеристики», ГОСТ Р 52292-2004 «Информационная технология. Электронный обмен информацией. Термины и определения», ГОСТ Р 52653-2006 
«ИКТ в образовании. Термины и определения», Р 50.1.031-2001 «Рекомендации по стандартизации. Информационные технологии поддержки жизненного цикла продукции. Терминологический словарь. Ч. 1. Стадии жизненного цикла продукции».

В целом проведенное исследование выявило ряд проблем, к числу которых следует отнести:

- несогласованность определений, используемых как в разных отраслях деятельности, так и в разных стандартах, входящих в один комплекс или систему стандартов, т. е. вариативность толкования одних и тех же понятий;

- некорректное обращение с терминами, имеющими дефиниции, закрепленные в нормативных документах;

- параллельное использование синонимичных терминов и понятий, в том числе в пределах одной сферы деятельности.

Безусловно, выявленные проблемы служат серьезным препятствием на пути эффективной коммуникации в условиях динамично развивающегося информационного общества.

\section{Формирование терминосистемы предметной области как важнейшее средство повышения эффективности коммуникаций в информационном обществе}

Анализ международной и российской нормативной базы свидетельствует о наличии разработанных, согласованных и закрепленных в стандартах принципах и правилах формирования терминосистемы в той или иной предметной области. Так, ГОСТ Р ИСО 704-2010 «Терминологическая работа. Принципы и методы» (GOST R ISO 704-2010, 2012) определяет в качестве цели терминологической работы прояснение и стандартизацию понятий и терминологии для общения между людьми. При этом отмечается, что «создание терминосистемы требует понимания той концептуализации, на которой основаны знания в отдельной предметной области. Поскольку терминосистемы всегда имеют дело со специальным языком конкретной области знания, понятие следует рассматривать не только как единицу мышления, но и как единицу знания». В соответствии с ГОСТ Р ИСО 704-2010 при формировании терминов целесообразно ориентироваться на следующие принципы: принцип прозрачности; принцип последовательности; принцип адекватности; принцип лингвистической экономии; принцип выводимости и сочлененности; принцип лингвистической корректности; принцип предпочтения родного языка (GOST R ISO 704-2010, 2012).

Учитывая вовлеченность практически всех граждан на различных уровнях в решение задач развития информационного общества, необходимо формирование терминосистемы данной предметной области. Для поддержания высоких темпов развития индустрии знаний и информационных ресурсов крайне важно иметь надежные языковые ресурсы. Таким образом, терминологическая информация становится ключевым элементом любых регуляционных действий. Терминологические данные могут служить множеству разных целей, из которых наиважнейшими являются:

- представление знаний (формулирование концептуальных понятий);

- упорядочение системы знаний (классификация понятий);

- обеспечение доступа к другим типам структурированного либо неструктурированного контента;

- предоставление средств или элементов коммуникации и передачи знаний (GOST R ISO 23185-2013, 2015).

В контексте современных требований к формированию понятийного аппарата в той или иной предметной области необходимо обеспечить разработку терминологической политики и осуществление терминологического планирования (GOST R ISO 29383-2012, 2014). В частности, терминологическая политика (terminology policy) формулируется на уровне принятия решений в языковой сфере, в предметной области или в профессиональном сообществе с целью разработки или регулирования развивающейся либо существующей тер- 
минологии различного назначения. Результатом терминологического планирования является развитие языковых ресурсов для поддержки информационного представления знаний (концептов) в конкретных предметных областях и использование таких представлений для обеспечения успешного и беспрепятственного общения специалистов в рамках конкретных предметных областей и при их взаимодействии, включая формирование терминологии, использование терминологии, ее документирование, регистрацию и обработку; передачу знаний, передачу терминологии, внедрение терминологии в практику, перевод, толкование и локализацию (GOST R ISO 293832012, 2014).

Таким образом, повышение эффективности коммуникации в условиях развития информационного общества требует решения ряда задач, в том числе:

- формирование единой терминосистемы предметной области «информационное общество», соответствующей требованиям нормативных документов;

- разработка классификации понятий, характеризующих информационное общество в целом и его компоненты;

- кумулирование понятийного аппарата предметной области «Информационное общество» в рамках отдельного комплекса стандартов;

- сопряжение понятийного аппарата, закрепляемого нормативно-правовыми и нормативно-техническими документами;

- разработка информационнопоисковых тезаурусов, комплексных справочных изданий в данной сфере.

\section{Список литературы}

Бачило, И.Л. (2016). Понятийный аппарат информационного права и система обеспечения информационной безопасности // Труды Института государства и права Российской академии наук, 3, 5-16.

Берестова, Т. (2017). Понятие «информационный ресурс» имеет право на существование. (Размышления, вызванные статьей Ю. Н. Столярова «Несостоятельностьпонятия «информационный ресурс»») // Научные и технические библиотеки, 7, 75-90.

Динер, Е.В. (2016). О необходимости уточнения дефиниций в проекте нового стандарта «Электронные документы. Основные виды, выходные сведения, технологические характеристики» // Научные и технические библиотеки, 3, 57-70.

ГОСТ Р 7.0.94-2015 (2016). СИБИД. Комплектование библиотеки документами. Термины и определения. Москва, Стандартформ, 26 с.

ГОСТ Р 7.0.96-2016 (2016). СИБИД. Электронные библиотеки. Основные виды. Структура. Технология формирования. Москва, Стандартформ, 12 с.

ГОСТ Р 43.0.9-2017 (2017). Информационное обеспечение техники и операторской деятельности. Информационные ресурсы. Москва, Стандартформ, 7 с.

ГОСТ Р 52653-2006 (2007). Информационно-коммуникационные технологии в образовании. Термины и определения. Москва, Стандартформ, 12 с.

ГОСТ Р ИСО 704-2010 (2012). Терминологическая работа. Принципы и методы. Москва, Стандартформ, 58 с.

ГОСТ Р ИСО 23185-2013 (2015). Оценка и сравнительный анализ терминологических ресурсов. Общие понятия, принципы и требования. Москва, Стандартформ, 24 с.

ГОСТ Р ИСО 29383-2012 (2014). Терминологическая политика. Разработка и внедрение. Москва, Стандартформ, 21 с.

Земсков, А. (2016). Терминология открытого доступа // Научные и технические библиотеки, 10, 54-58.

Камалов, А. (2015) Электронный документ: трудности определения // Научные и технические библиотеки, 3, 66-82.

Колкова, Н. Скипор, И. (2016). Терминосистема предметной области «электронные информационные ресурсы»: взгляд с позиций теории и практики // Hаучные и технические библиотеки, 7, 24-41. 
Наумов, В.Б. (2018). Негативные закономерности формирования понятийного аппарата в сфере регулирования Интернета и идентификации // Информационное право, 1, 32-39.

Об информации, информационных технологиях и о защите информации (2006). Федеральный закон от 27.07.2006 N149-Ф3. Режим доступа: http://www.consultant.ru/document/ cons_doc LAW_61798

О Стратегии развития информационного общества в Российской Федерации на 2017-2030 годы (2017). Указ Президента РФ от 09.05.2017 N203. Режим доступа: http://www.garant.ru/products/ipo/ prime/doc/71570570/

Столяров, Ю.Н. (2016). Несостоятельность понятия «информационный ресурс» // Научные и технические библиотеки, 3, 52-56.

Столяров, Ю.Н. (2016). Open Access = свободный (!) доступ [Open Access = free (!) access] // Научные и технические библиотеки, 10, 63-69

Сукиасян, Э.Р., Зверевич, В.В., Бахтурина, Т.А. (2013). Русско-английский словарь по библиотечной и информационной деятельности. Санкт-Петербург: Профессия, 224 с.

Шрайберг, Н.Д. (2016). К дискуссии о термине «открытый доступ» // Научные и технические библиотеки, 10, 70-71.

\section{References}

Bachilo, I.L. (2016). Poniatiinyi apparat informatsionnogo prava i sistema obespecheniia informatsionnoi bezopasnosti [Conceptual apparatus of information law and information security system]. In Trudy Instituta gosudarstva i prava Rossiiskoi akademii nauk [Proceedings of the Institute of State and Law of the Russian Academy of Sciences], 3, 5-16.

Berestova, T. (2017). Poniatie informatsionnyi resurs imeet pravo na sushchestvovanie Razmyshleniia vyzvannye statei IU N Stoliarova Nesostoiatelnost poniatiia informatsionnyi resurs [Information resource notion has the right to existence (Reflection caused by Yu. Stolyarov's article «Groundlessness of the Information resource notion»)]. In Nauchnye i tekhnicheskie biblioteki [Scientific and Technical Libraries], 7, 76-91.

Diner, E. (2016). O neobkhodimosti utochneniia definitsii v proekte novogo standarta Elektronnye dokumenty Osnovnye vidy vykhodnye svedeniia tekhnologicheskie kharakteristiki [On the need to refine definitions in the draft standard»Electronic documents. Main types, imprint, terminology specifications»]. In Nauchnye i tekhnicheskie biblioteki [Scientific and Technical Libraries], 3, 57-70.

GOST R7.0.94-2015 (2016). SIBID. Komplektovanie biblioteki dokumentami. Terminy i opredeleniia [Acquisition of library collection. Terms and definitions]. Moskow, Standartinform, $26 \mathrm{p}$.

GOST R7.0.96-2016 (2016). SIBID. Elektronnye biblioteki. Osnovnye vidy. Struktura. Tekhnologiia formirovaniia [Digital libraries. Basic tapes. Structure. Development technology]. Moskow, Standartinform, $12 \mathrm{p}$.

GOST R43.0.9-2017 (2017). Informatsionnoe obespechenie tekhniki i operatorskoi deiatelnosti Informatsionnye resursy [Informational ensuring of equipment and operational activity. Information resources]. Moskow, Standartinform, $7 \mathrm{p}$.

GOST R52653-2006 (2007). IKT v obrazovanii. Terminy i opredeleniia [Information and communication technologies in education. Terms and definitions]. Moskow, Standartinform, 12 p.

GOST R ISO 704-2010 (2012). Terminologicheskaia rabota. Printsipy i metody [Terminology work. Principles and methods]. Moskow, Standartinform, 58 p.

GOST R ISO 23185-2013 (2015). Otsenka i sravnitelnyi analiz terminologicheskikh resursov Obshchie poniatiia printsipy i trebovaniia [Assessment and benchmarking of terminological resources. General concepts, principles and requirements]. Moskow, Standartinform, $24 \mathrm{p}$.

GOST R ISO 29383-2012 (2014). Terminology policies. Development and implementation. Moskow, Standartinform, $21 \mathrm{p}$.

Kamalov, A. (2015). Elektronnyi dokument trudnosti opredeleniia [Electronic document: Complexities of definition]. In Nauchnye i tekhnicheskie biblioteki [Scientific and Technical Libraries], 3, 66-82. 
Kolkova, N., Skipor, I. (2016). Terminosistema predmetnoi oblasti elektronnye informatsionnye resursy vzgliad s pozitsii teorii i praktiki [Term-system of the subject area of digital resources: from the viewpoint of theory and practice]. In Nauchnye i tekhnicheskie biblioteki [Scientific and Technical Libraries], 7, 24-41.

Kuzmina, I.D., Bogdanova, I.S. (2019). Some problems of digital environment influence on the content of civil law object and subject categories. J. Sib. Fed. Univ. Humanit. soc. sci., 12(3), 393-409. DOI: 10.17516/1997-1370-0401.

Naumov, V.B. (2018). Negativnye zakonomernosti formirovaniia poniatiinogo apparata $\mathrm{v}$ sfere regulirovaniia Interneta i identifikatsii. [Negative patterns of the formation of the conceptual apparatus in the field of Internet regulation and identification]. In Informatsionnoe parvo [Information law], 1, 32-39.

$\mathrm{Ob}$ informatsii informatsionnykh tekhnologiiakh i o zashchite informatsii [About information, information technology and information protection] (2006). Federalnyi zakon utv. 27.07.2006 no. 149-FZ [Federal Law of 27.07.2006 N149-FZ]. Available at: http://www.consultant.ru/document/cons_doc_LAW_61798

Petrova, O.V. (2018). Cultural, communicative and relevance factors as the bases for decision making in translation. In J. Sib. Fed. Univ. Humanit. soc. sci., 11(9), 1453-1466. DOI: 10.17516/1997-1370-0315.

Shrayberg, Y.L. (2016). K diskussii o termine otkrytyi dostup [To the discussion on the term «Open Access»]. In Nauchnye i tekhnicheskie biblioteki [Scientific and Technical Libraries], 10, 70-71.

Stolyarov, Y.N. (2016). Nesostoiatelnost poniatiia informatsionnyi resurs [«Information resource»: Inconsistency of the term]. In Nauchnye i tekhnicheskie biblioteki [Scientific and Technical Libraries], 3, $52-56$

Stolyarov, Y.N. (2016). Open Access = svobodnyi dustup (!) [Open Access = free (!) access]. In Nauchnye i tekhnicheskie biblioteki [Scientific and Technical Libraries], 10, 63-69

Strategiia razvitiia informatsionnogo obshchestva v Rossiiskoi Federatsii na 2017-2030 gody [About the Strategy for the Development of the Information Society in the Russian Federation for 2017-2030] (2017). utv. Ukazom Prezidenta RF ot 9.05. 2017 № 203 [Decree of the President of the Russian Federation of 05.09.2017 N203]. Available at: http://www.garant.ru/products/ipo/prime/doc/71570570/

Sukiasyan, E., Zverevich, V., Bakhturina, T. (2013). Russko-angliiskii slovar po bibliotechnoi $i$ informatsionnoi deiatelnosti [Russian-English Dictionary of Library and Information Terminology]. SanktPeterburg: Professiia, 224 p.

Zemskov, A. (2016). Terminologiia otkrytogo dostupa [Open Access terminology]. In Nauchnye i tekhnicheskie biblioteki [Scientific and Technical Libraries], 10, 54-58. 